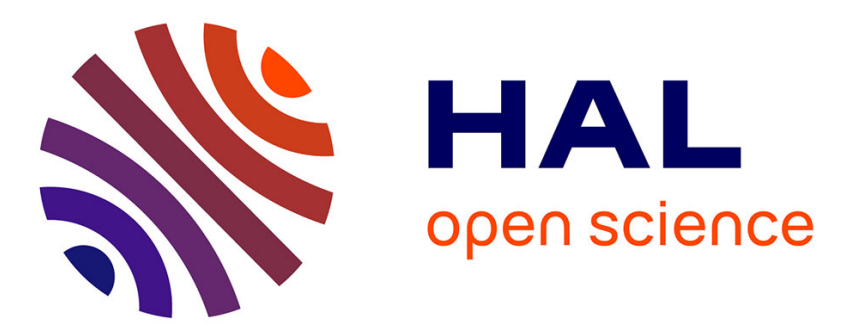

\title{
Local adaptations of life-history traits of a Drosophila parasitoid, Leptopilina boulardi: does climate drive evolution?
}

\author{
Joffrey Moiroux, Cécile Le Lann, Majeed A Seyahooei, Philippe Vernon, \\ Jean-Sébastien Pierre, Joan van Baaren, Jacques J.M. van Alphen
}

\section{To cite this version:}

Joffrey Moiroux, Cécile Le Lann, Majeed A Seyahooei, Philippe Vernon, Jean-Sébastien Pierre, et al.. Local adaptations of life-history traits of a Drosophila parasitoid, Leptopilina boulardi: does climate drive evolution?. Ecological Entomology, 2010, 35 (6), pp.727-736. 10.1111/j.13652311.2010.01233.x . hal-02020957

\section{HAL Id: hal-02020957}

\section{https://hal-univ-avignon.archives-ouvertes.fr/hal-02020957}

\author{
Submitted on 15 Feb 2019
}

HAL is a multi-disciplinary open access archive for the deposit and dissemination of scientific research documents, whether they are published or not. The documents may come from teaching and research institutions in France or abroad, or from public or private research centers.
L'archive ouverte pluridisciplinaire HAL, est destinée au dépôt et à la diffusion de documents scientifiques de niveau recherche, publiés ou non, émanant des établissements d'enseignement et de recherche français ou étrangers, des laboratoires publics ou privés. 
Local adaptations of life history traits of a Drosophila parasitoid, Leptopilina boulardi: does climate drive evolution?

Joffrey Moiroux ${ }^{1,2}$, Cécile Le Lann ${ }^{1}$, Majeed A. Seyahooei ${ }^{2}$, Philippe Vernon ${ }^{1,3}$, JeanSébastien Pierre ${ }^{1}$, Joan van Baaren ${ }^{1}$ and Jacques J.M. van Alphen ${ }^{1,2}$

${ }^{1}$ Université de Rennes 1, UMR CNRS 6553, 263 Avenue du Général Leclerc, CS 74205, 35042 Rennes Cedex, France.

${ }^{2}$ Institute of Biology, Leiden University, PO Box 9516, 2300 RA Leiden, The Netherlands.

${ }^{3}$ Station Biologique de Paimpont, Université de Rennes 1, UMR CNRS 6553, 35380 Paimpont, France. 


\begin{abstract}
1. Climate is an important source of selection on life histories, and local adaptations to climate have been described in several cline studies. Temperature is the main climatic factor that has been considered as an agent of selection, whereas other factors may vary with it, such as precipitation.
\end{abstract}

2. We compared life-history traits of five populations of Leptopilina boulardi, a Drosophila parasitoid, originating from contrasting climates. Referring to cline studies, we hypothesised shorter lifespan, earlier reproduction, and lower lipid content in populations from the hottest and driest areas if life histories have been selected in response to temperature and/or humidity.

3. Our results are opposite to these predictions. Females from humid and mild climates invested more in early reproduction and lived for fewer days than females from dry and hot areas, which were synovigenic (i.e. they matured additional eggs during adult life) and able to synthesise lipids during adult life.

4. We suggest that life histories are more adapted to host distribution than to climatic factors. Drosophila patches are more abundant in the humid area, allowing the parasitoids to spend less energy and time finding hosts. This may result in selection for early reproduction tradedoff against longevity. In the hot and dry climate, females have to fly large distances to find host patches. Synovigeny, a long lifespan, lipogenesis, and high dispersal ability may be adaptive there. This is the first time that between-population differences in the ability to synthesise lipids have been described in parasitoids.

Key words: Life-history theory, reproductive strategies, trade-offs, temperature, precipitation, resource distribution, parasitoids 


\section{Introduction}

Life histories evolve in response to environmental conditions (Stearns, 1992). In the last decade, climate as a selective factor has been well investigated as it can affect physiology and/or behaviour of organisms, particularly that of ectotherms. Genetic differences due to climate-dependent selection onlife-history traits have been shown in several studies of geographic variation, where populations originating from cold and hot climates have been compared in common garden experiments (e.g. Liefting et al., 2009). Comparative studies of populations of insect species, particularly Drosophilidae, at a continental scale or along an altitudinal cline have documented between-population variation of several but isolated lifehistory and morphological traits. For example, increase in thorax length (Dahlgaard et al., 2001) and decrease in knock-down resistance (Sørensen et al., 2005) with an increase in altitude have been recorded in Drosophila buzzati, while starvation resistance increases with increasing latitude in Drosophila burchii (Griffiths et al., 2005).

Environmental conditions do not only affect one or more traits in isolation but can affect the balance of allocation of resources to a large range of life-history traits. For example, development time generally decreases with increasing temperature but adult body size also decreases in a majority of insects studied (Sibly \& Atkinson, 1994). Fecundity also increases with temperature whereas longevity decreases, as a trade-off occurs between these two traits (Nunney \& Cheung, 1997). Thus reproductive allocation strategies and trade-offs can show clinal variation, e.g. an increase in early reproduction with altitude traded off against a shorter lifespan (Norry et al., 2006). Correlations between traits involve studying a large range of traits when interested in climate-dependent evolution of life histories and that consideration has to be taken into account in comparative studies.

Most studies considered only a temperature gradient to explain evolution of life-history traits but humidity and precipitation gradients that occur on a cline should also be explored. 
Desiccation resistance is the only life-history trait that has been considered as a result of differences in humidity (Karan et al., 1998; Gilchrist et al., 2008) but other traits may be under selection of humidity and precipitation, such as timing of egg-laying. Here we propose a study on local adaptations of a large range of life-history traits in a Drosophila parasitoid, Leptopilina boulardi, to understand how resource allocation strategies have evolved in response to climate. We compared populations originating from a mild and humid area with populations from a very dry and hot desert area and a population from a cool environment but intermediate in precipitation. We considered temperature and humidity gradients as climatic factors that may result in adaptation of life histories.

As no formal theory exists about the impact of temperature on life histories, we used data from empirical studies to formulate hypotheses. The few cline studies that have been published can be used to make predictions about the impact of temperature on selection in several life-history traits in insects. In altitudinal and latitudinal clines studies, lifespan (Schmidt et al., 2005; Schmidt \& Paaby, 2008) of Drosophila melanogaster females, the main host of L. boulardi, from colder environments exceeds that of females from hotter areas while their reproduction is delayed (Mitrovski \& Hoffmann, 2001; Schmidt et al., 2005; Schmidt \& Paaby, 2008). Moreover, a low wing loading [i.e. the ratio of fresh mass to wing surface that corresponds to the pressure exerted by the wings on the surrounding air (Gilchrist \& Huey, 2004)] is thought to be selected under cool conditions to compensate the lower wing beat frequency at lower temperatures in insects (Unwin \& Corbet, 1984). Compared with cold or mild environments, we can expect that lifespan of the parasitoid wasps from the hottest environment may be reduced. This shorter lifespan may have resulted in the selection of an early reproduction traded-off against lower lipid content at emergence as a trade-off generally occurs between these two traits in parasitic wasps (Ellers \& van Alphen, 1997). Lipids have to 
be considered when investigating parasitoids life histories as they represent the main energetic resources allocated to survival and reproduction in parasitoids.

Importance of humidity in selection of life histories has been poorly investigated and no cline studies can be used to make predictions because only temperature has been considered as an explanative factor. However similar results of selection for the driest areas as in the hottest areas may be expected as lifespan may be reduced because of a high risk of desiccation and early reproduction may be adaptive in very dry environments where favourable reproductive periods are relatively short in comparison to humid environments.

To resume, compared with cold and dry or mild and humid environments, we may observe shorter lifespan, earlier reproduction, lower lipid content and higher wing loading in populations from the hottest and driest areas. We discuss our results in the light of the abovementioned predictions for the importance of temperature and humidity in the selection of life histories. 


\section{Material \& Methods}

Leptopilina boulardi (Hymenoptera: Figitidae) is a solitary endoparasitoid that mainly attacks D. Melanogaster and D. simulans larvae (Diptera: Drosophilidae) living in fermenting fruits. This species occurs principally in regions with a Mediterranean climate and in tropical Africa. Leptopilina boulardi females have been described as proovigenic (Kopelman \& Chabora, 1986), i.e. they mature all their eggs before the start of their adult life.

\section{Source of laboratory samples}

Five populations of $L$. boulardi from contrasting climates (Table 1) were collected in Iran (Fig. 1) in July 2006 using twelve banana bait traps per site. Each open trap (i.e. a plastic container with a $3 \mathrm{~cm}$ diameter hole covered with a mesh with $2 \mathrm{~mm}$ openings) was colonised by five to twenty females and several hundreds of offspring were produced in each of them. Leptopilina boulardi and L. heterotoma were the only parasitoids and Drosophila melanogaster and D. simulans were the only fruit flies we found in our traps in all locations. From the offspring thirty females per population were taken to set up lab cultures. Two populations - Chalus and Seyakhal - originated from a humid and mild environment, in the coastal plain of the Caspian Sea where orchards, the main habitat for fruit flies, and fruit trees are abundant during a long season. Moreover, there are a lot of forests where Drosophila can be found in the area. Dorcheh and Zamankhan strains originated from a hot and very dry area, although the location of our traps was in the valley of a river fed by melting snow from the mountains that keeps also water throughout summer and allows for agriculture under irrigation in a narrow zone bordering the river. In this area, fruits are produced in few and distant orchards. These few orchards represent the only habitat where fruit flies are present as the remaining area is desert. The last strain - Sorkhabad - originated from the Alborz 
Mountains, with the coolest climate but intermediate in humidity and number of rainy days between Chalus/Seyakhal and Dorcheh/Zamankhan. These five localities have been chosen within a relatively small area in comparison to continental-scales studies to compare populations with recent isolation (less than $100 \mathrm{~km}$ between Seyakhal, Chalus and Sorkhabad and between Zamankhan and Dorcheh, $400 \mathrm{~km}$ between Dorcheh/Zamankhan and Chalus/Seyakhal/Sorkhabad).

We carried out between-populations crossings to ensure that all populations indeed belonged to the same species, L. boulardi. For each population, five crossings were performed with males of the other strains. We obtained fertile females in all crossings confirming the conspecificity of the populations, as only inseminated mothers can produce females in haplodiploid species.

\section{Cultures}

Drosophila melanogaster used as hosts in the cultures originated from strains collected in the Netherlands in 1960 . Ten $L$. boulardi females oviposited in separate jars for $48 \mathrm{~h}$ in 100 to 120 second instar D. melanogaster larvae laid in a two hours period (similar size for every host) in a baker's yeast suspension. The parasitized larvae were reared at $25^{\circ} \mathrm{C}, 50 \% \mathrm{RH}, 12 \mathrm{~L}: 12 \mathrm{D}$ in glass jars on an Agar-Nipagine substrate. This temperature was chosen as it is the one at which a maximum of offspring is produced for all populations. Progeny of a same mother was separated in three groups. The first one was used for measurements of morphometric traits, number and volume of eggs and lipid content, the second one for the measurement of longevity and the last one to measure activity. Adults were fed with diluted acacia honey distributed ad libitum. 
Presence of Lbfv virus. Varaldi et al. (2003) described the presence of Lbfv viral particles in some L. boulardi populations and showed that this virus causes an increased tendency to superparasitize in infected females. These viral particles are also involved in changes in other life history traits such as egg load. We first checked the presence or absence of superparasitism to be sure that the virus could not explain variations in other life history traits between populations. We used a protocol similar to the one described by Varaldi et al. (2003). All the experiments were conducted at $25^{\circ} \mathrm{C}$. Twenty females ( 24 to $48 \mathrm{~h}$ old) originating from each population were isolated for 16 hours (from $6 \mathrm{pm}$ to $10 \mathrm{am}$ ) with ten Drosophila melanogaster larvae (48h old) foraging in an arena consisting of a thin yeast spot spread over an agar layer poured into a $5 \mathrm{~cm}$ diameter Petri dish. After two days of incubation, Drosophila larvae were dissected and parasitoid eggs were counted to estimate superparasitism.

No self-superparasitism occurred in our experiments. We never found more than a single egg per parasitized larva in experiments with females from all five populations. There is thus no evidence for the presence of the virus Lbfv in these populations. Hence, Lbfv can not explain between-populations differences in egg load and other life history traits.

\section{Life history traits}

Morphometric traits, number and volume of eggs and lipid content were measured on twenty females from each population at 24 hours, five days and ten days after emergence except for Sorkhabad strain which had been lost before measurements at five and ten days of life. Females were placed in Eppendorf tubes, frozen in liquid nitrogen to stop all metabolic activity instantaneously and conserved at $-80^{\circ} \mathrm{C}$. These females constituted the first group of individuals. 
Morphometric traits. After defrosting, fresh mass (FM) was determined with a microbalance (Sartorius M4 $\pm 0.001 \mathrm{mg})$ while left wing length was measured $( \pm 0.01 \mathrm{~mm})$ with the numeric image analysis software Pegasus Pro V4 under a binocular linked to a camera video (JVC KY-F). Wing loading was then calculated as the ratio of fresh mass to squared wing length. Wing loading corresponds to the pressure exerted by the wings on the surrounding air (Gilchrist \& Huey, 2004). Thus the cost of transport is influenced in an important way by the wing area that supports the body mass (Starmer \& Wolf, 1989). The lower the wing loading, the less costly the flight is.

Investment in early and lifetime reproduction. Females used for morphometric traits were placed in a drop of Ringer's solution on a microscope slide and dissected under a binocular $(\times 40$, Olympus SZX9). Eggs were removed from both ovaries and counted, while the rest of the female's body was conserved for later lipids extraction. After counting, eggs were placed under a microscope ( $\times 4$, Olympus BH2) and photographed (Olympus Camedia C3040). Length (L) and width (w) of 30 eggs of each female were measured with the numeric image analysis software AnalySIS to calculate eggs volume (taken as a prolate spheroid volume: $\left.\mathrm{V}=4 / 3 \pi \mathrm{Lw}^{2}\right)$. Investment in reproduction was calculated as the result of number of eggs*volume of eggs. This parameter is a measure of energy invested into reproduction.

Lipid content. After eggs had been removed from all the females measured of different ages, we measured lipid quantity of the females using the protocol proposed by Vernon \& Vannier (1996) and Terblanche et al. (2004). Wasps were dried at $40{ }^{\circ} \mathrm{C}$ during four days in an air oven and weighed to measure dry mass. Then parasitoids were left during two weeks in an Eppendorf tube containing $1 \mathrm{ml}$ of chloroform/methanol solution (2:1) to extract lipids. Then females were again placed at $40^{\circ} \mathrm{C}$ during 24 hours and weighed again to measure lipid 
quantity and lipid content (=lipid quantity/lean dry mass). This lean dry mass (without eggs) was used as an indication of body size in our statistical analyses.

Longevity. This parameter was measured in the second group of wasps $(n=20$ per population). Females from each population were placed at $25^{\circ} \mathrm{C}$ on an Agar-Nipagine substrate and were fed with honey. The substrate was renewed every two weeks. Dead individuals were counted and removed twice a day, each morning and evening.

Activity. This parameter was measured in the third group of individuals $(n=20$ per population for Chalus, Seyakhal and Zamankhan strains). The behavioural data acquisition and analysis software Ethovision (Noldus Information Technology 1997) allowed us to record and analyze locomotive activity of parasitoids. Females were fed with honey during the first 24 hours of their adult life. Then they were isolated in Petri dishes $(\varnothing 5 \mathrm{~cm})$ thirty minutes before the start of the recording. For each run, four one-day old females belonging to the three populations were filmed simultaneously (camera Panasonic CCTV) in a windowless room during 24 hours: 12 hours with artificial light and 12 hours with red light only, simulating night.. The contrast between individuals and a white background was used to detect females and record their position twelve times per minute. The total distance covered and the average velocities were automatically calculated from the track records.

\section{Statistical analysis}

\section{Variations in life history traits between populations.}

Correlations between body size parameters (i.e. fresh mass, lean dry mass and wing length) and (1) reproductive parameters and lipid reserves for the first group and (2) longevity for the 
second group and (3) activity for the third group of individuals were examined for each population and for the complete data set.

ANCOVA and ANOVA were performed to analyze the effect of population and age on the different traits mentioned above. Post hoc tests were done to compare individuals of a same age from different populations and individuals of different ages within a population. Analyses of covariance (ANCOVA) were used when a correlation occurred between the trait tested and body size to remove any effect of size from the measurement and ANOVA tests were used when no correlation was detected.

The number of eggs $\left(\mathrm{r}^{2}=0.6, \mathrm{P}<0.0001\right)$ and lipid quantity $\left(\mathrm{r}^{2}=0.64, \mathrm{P}<0.0001\right)$ increased with lean dry mass but the volume of eggs and activity were neither correlated with lean dry mass $(\mathrm{P}>0.05)$ nor fresh mass $(\mathrm{P}>0.5)$ respectively. No correlation was found between longevity and dry mass in any population $(\mathrm{P}>0.05)$.

Thus we used ANCOVA to examine differences in number of eggs, in investment in reproduction and in lipid quantity by incorporating lean dry mass as a covariate. ANCOVA was also used to test differences in squared wing length using fresh mass as a covariate. This test was performed to compare wing loading. Differences in the volume of eggs and in activity (i.e. total covered distance and velocity) were analysed with ANOVA. Differences in activity between day and night for a population were tested with Student's t tests.

The survival package provided by $\mathrm{R}$ software was used to test differences in longevity between populations, using a Weibull distribution.

\section{Climatic factors in selection of life-histories.}

We made Generalized Linear Models using the global dataset of populations to test for correlations between all life history traits and climatic factors: air temperature, thermal amplitude, relative humidity, number of rainy days and precipitation. Climatic factors were 
included in the base model and removed one by one to obtain the minimum adequate model. The selection was done on the basis of the AIC criterion (Akaike Criterion, Akaike 1974). Pvalues reported are those of the last model that contains the variables.

All analyses were carried out using R software version 2.5.0 (R Development Core Team, 2007).

\section{Results}

\section{Variations in life history traits between populations.}

Wing loading (Fig. 2). Females from Chalus, Seyakhal and Sorkhabad had a similar wing loading. Dorcheh and Zamankhan females had a similar wing loading but lower than the other populations (ANCOVA, $\mathrm{F}=48.98, \mathrm{df}=5, \mathrm{P}<0.0001$ ). Wing loading did not differ between the different ages for Chalus, Seyakhal and Sorkhabad populations but it increased in Zamankhan (ANCOVA, $\mathrm{F}=48.25, \mathrm{P}<0.001)$ and Dorcheh $($ ANCOVA, $\mathrm{F}=29.4, \mathrm{P}<0.001)$ populations between five days and ten days of adult life as their fresh mass increased.

Investment in early and lifetime reproduction (Fig. 3). For the same lean dry mass, females originating from Chalus and Seyakhal emerged with more eggs than Dorcheh and Zamankhan females (ANCOVA, $\mathrm{F}=83.36$, df $=5, \mathrm{P}<0.0001$ ) (Fig 3A, $<24$ hours). Sorkhabad individuals emerged with an intermediate number of eggs.

No change in number of eggs was observed in Chalus females (ANOVA, $\mathrm{F}=0.008$, $\mathrm{df}=2, \mathrm{P}$ $=0.96$ ) or Seyakhal (ANOVA, $\mathrm{F}=0.005, \mathrm{df}=2, \mathrm{P}=0.99$ ) between 24 hours and ten days of adult life. Dorcheh females increased the number of eggs in their ovaries (ANOVA, F = 
12.67, $\mathrm{df}=2, \mathrm{P}<0.001)$ during the first five days of adult life $(\mathrm{P}=0.012)$ but no change was observed between five and ten days $(\mathrm{P}=0.99)$. Zamankhan females increased the number of eggs in their ovaries during the first ten days of adult life (ANOVA, F $=6.7$, df $=2, \mathrm{P}<$ 0.001) (Fig. 3A).

The Chalus wasps had smaller eggs than the other populations (ANOVA, $\mathrm{F}=2.69, \mathrm{P}=0.03$ ) which did not differ between each other. We did not observe any difference in the volume of eggs in any of the populations between the three ages (ANOVA, $\mathrm{P}>0.6$ ). We found a negative correlation between the number and the volume of eggs in Chalus females $\left(r^{2}=0.53\right.$, $\mathrm{P}<0.001)$. This correlation was not found in any other population $(\mathrm{P}>0.05)$.

Chalus and Seyakhal females invested more in early reproduction (i.e. number of eggs*volume of eggs, corrected by lean dry mass) than Dorcheh and Zamankhan females while Sorkhabad individuals had an intermediate investment in early reproduction (ANCOVA, F = 4.078, $\mathrm{P}<0.0001$ ). (Fig. 3B).

\section{Lipid content (Fig. 4).}

Chalus, Seyakhal and Sorkhabad populations had similar lipid contents and females of these populations emerged with a higher lipid content than Dorcheh and Zamankhan females (ANCOVA, $\mathrm{F}=48.98, \mathrm{P}<0.0001)($ Fig. 4A).

No change in lipid content was observed for Chalus (ANCOVA, F =0.009, P = 0.97) and Seyakhal females (ANCOVA, $\mathrm{F}=0.007, \mathrm{P}=0.99$ ) during adult life. In contrast, females of the Dorcheh (ANCOVA, $\mathrm{F}=9.27, \mathrm{P}<0.001$ ) and Zamankhan populations (ANCOVA, $\mathrm{F}=$ $11.28, \mathrm{P}<0.001)$ increased their lipid content considerably during the first ten days of adult life (Fig. 4B).

Within populations, negative correlations were found for all populations between number of eggs and lipid content $\left(n=20, r^{2}=(0.34-0.63), P<0.05\right)$. 
Longevity. Seyakhal females had the shortest lifespan (longevity $=11.5 \pm 1.47$ days, mean \pm SE) while Zamankhan females lived significantly longer (longevity $=21.7 \pm 0.82$ days) than females of any other population (Survival analysis, Chisq $=65.46, \mathrm{P}<0.005$ ). Dorcheh females (longevity $=20.2 \pm 0.7$ days) lived longer than Sorkhabad (longevity = 18.7 \pm 0.91 days) and Chalus individuals (longevity $=17 \pm 1.7$ days) that had a similar longevity.

Activity (Fig. 5). Seyakhal and Chalus females covered significantly shorter distances than Zamankhan females during the experiments (ANOVA, $\mathrm{F}=8.497$, $\mathrm{df}=2, \mathrm{P}<0.05$ ). The same pattern was found for velocity (ANOVA, $\mathrm{F}=4.522$, df $=2, \mathrm{P}<0.05$ ). Moreover, Chalus (Student's test, $\mathrm{t}=2.18, \mathrm{df}=19, \mathrm{p}=0.032$ ) and Seyakhal (Student's test, $\mathrm{t}=2.79, \mathrm{df}=19, \mathrm{p}$ $=0.015$ ) females were more active during day while Zamankhan individuals were more active during night (Student's test, $\mathrm{t}=-4.95, \mathrm{df}=19, \mathrm{P}<0.005$ ).

\section{Climatic factors in selection of life-histories (Fig. 6).}

Climatic factors explained patterns for wing loading $(\mathrm{t}=2.625, \mathrm{P}<0.0001)$ and investment in early reproduction $(\mathrm{t}=7.73, \mathrm{P}<0.0001)$, lipid content $(\mathrm{t}=4.8, \mathrm{P}<0.0001)$, and longevity $(\mathrm{t}=$ 10.95, $\mathrm{P}<0.001)$. For these life history traits, the minimum adequate generalized linear models excluded air temperature and thermal amplitude as explanatory factors but included relative humidity, number of rainy days and amount of precipitation.

Investment in early reproduction (Fig. 6A), lipid content at emergence, and wing loading increased with these factors but longevity decreased (Fig. 6B). 


\section{Discussion}

Compared to females from mild and wet environment (Chalus and Seyakhal) and females from cool environment and intermediate in precipitations (Sorkhabad), females from hot and very dry environments (Dorcheh and Zamankhan) invested less in early reproduction and had a longer lifespan, lower lipid contents and wing loading during the first twenty-four hours of adult life. Females from the coolest climate but intermediate in precipitations and relative humidity (Sorkhabad) invested an intermediate amount of energy into early reproduction and longevity. Our results are not consistent with other latitudinal cline studies on adaptations of life history traits to temperature (e.g. Schmidt et al., 2005, Schmidt \& Paaby, 2008, Mitrovski \& Hoffmann, 2001, Gilchrist \& Huey, 2004).

Our parasitic wasps were collected in a relatively small area in comparison to the above cited latitudinal cline studies on Drosophilidae. The mean temperatures of our coolest and hottest climate were respectively $24.4^{\circ} \mathrm{C}$ and $31.6^{\circ} \mathrm{C}$. Thus, our temperature range was quite smaller but on average warmer than in the other cline studies. This could possibly explain why we did not obtain similar results. Moreover, only Drosophila species were studied until now and parasitoids may respond differently to selection by temperature. Yet, one would expect that temperature should have similar effects in all ectotherms as it directly affects their physiology.

We therefore think that it is more likely that differences in life histories between our populations result from selection by another environmental factor than temperature. We considered precipitation and humidity in our study as possible agents of selection and found a strong link between number of rainy days/ precipitation amount and life history traits (i.e. investment in early reproduction, longevity, wing loading and lipid reserves). This result suggests that precipitation may be more important than temperature in selection of lifehistories. 
To our knowledge, no evidence of direct effect of humidity on selection of life history traits has been shown except for desiccation resistance (Gilchrist et al., 2008, Karan et al., 1998), but patterns for this trait are not really clear. Other studies on a humidity-dependent selection are needed to understand if this climatic factor may directly affect other life history traits than desiccation resistance.

A difference in climate involves more than only the abiotic environment as it may also affect the biotic environment e.g. interspecific interactions in the community or distribution of resources. We did not collect any other parasitoid species than L. boulardi and L. heterotoma in all locations so there is no evidence that differences in interspecific competition may explain differences in life history traits. Moreover, it is unlikely that variation in host species may explain differences between populations as we only found $D$. melanogaster and $D$. simulans in our traps. Our sampling areas differed in climate but also in landscape and biotic environment. Water availability determines fruit distribution -the main source of food for Drosophila melanogaster- and therefore laying opportunities for parasitoids. In the mild and humid area (Chalus and Seyakhal), there is a lot of precipitation during the whole season so fruits, and therefore Drosophila are common throughout the season. In the desert area (Dorcheh and Zamankhan), the lack of precipitation during summer restricts the production of fruits to few and distant areas under irrigation. Here, subsequent populations of parasitoids have to move between crops of different fruits, because when they emerge as adults, the season for the fruit in which they developed is over. This necessitates long flights in search of host habitats. Thus we will mainly explain our results on life history traits in the light of a selection in response to host distribution as it is affected by humidity.

\section{Reproductive strategies and longevity.}


We found a high investment in early reproduction of females from mild and wet environments (Chalus and Seyakhal), correlated with a shorter lifespan. These results suggest that females from these populations are pro-ovigenic i.e. they do not mature eggs during adult life but females were not allowed to lay eggs. According to models developed by Ellers et al. (2000) and Ellers \& Jervis (2004), host distribution is the most important factor resulting in the selection of pro-ovigeny and may explain our results: in environments with small distances between host patches and a high encounter rate with hosts, selection results in the allocation of energy to early reproduction (i.e. pro-ovigeny) at the cost of a shorter lifespan.

Sorkhabad females originate from the coldest area where rainy days and the precipitation amount are intermediate between Chalus/Seyakhal and Zamankhan/Dorcheh. Investment in early reproduction and longevity were both intermediate in Sorkhabad females. The results for this population supports the fact that precipitation and not temperature is important in selection on reproductive strategies.

Females from the desert area (Dorcheh and Zamankhan) invested less in early reproduction but lived longer than other populations. Our results also provide evidence that Leptopilina boulardi is not a completely pro-ovigenic species as suggested by Kopelman \& Chabora (1986): we observed an increase of more than 50 eggs during the first ten days of adult life in Dorcheh and Zamankhan females. Females from these populations were synovigenic (i.e. they still mature eggs during adult life) and lived longer than those of other populations. Synovigeny and increased lifespan allow a plastic response in an environment where females have to move over large distances to find hosts and are time-limited (Ellers \& van Alphen 1997). They can adjust egg maturation to the laying opportunities and trade current for future reproduction. This could explain the synovigeny in the Dorcheh and Zamankhan populations. Our results suggest that pro-ovigenic and synovigenic populations may occur within the same parasitoid species. Such variation in reproductive strategies between populations has never 
been described in parasitoids. Therefore, we have to confirm the pro-ovigeny of Seyakhal and Chalus females by providing them hosts and checking if laying opportunities lead to the maturation of additional eggs during adult life (i.e. synovigeny) or not (strict pro-ovigeny) in these populations.

Variations in life history traits between populations suggested that a trade-off occurs between longevity and investment in early reproduction. However, this trade-off was not found for females after five days of adult life because Zamankhan females, that lived longer, matured additional eggs while females from mild and humid area did not. Females were not limited by carbohydrate resources in our fecundity experiments, and thus could allocate more of their lipid reserves to reproduction. In nature, female parasitoids from the desert area are food and time limited because they have to travel long distances to find patches of hosts and sources of food. Thus a trade-off may occur between longevity and realised fecundity that we did not detect here because females were not allowed to lay eggs and were fed ad libitum.

Lipid content. In parasitoids, a longer lifespan is often associated with higher lipid reserves at emergence (Ellers, 1996; Rivero \& West, 2002) when initial egg load is traded-off against fat reserves (Ellers \& van Alphen, 1997). Indeed we observed a negative correlation between initial number of eggs and lipid content for the five populations studied. A trade-off between fecundity and lipid reserves exists during larval development where resources are limited by the amount available from the host.

Surprisingly, females from the dry and hot area lived longer than females from the other areas but emerged with smaller lipids reserves. Parasitoids were thought to be unable to synthesize and accumulate lipids during adult life and to depend only on lipids accumulated during larval development (Giron \& Casas, 2003; Visser \& Ellers, 2008). However Visser et al. (2010) recently described lipogenesis in some parasitoid species and suggest that "the wide range of 
host species in which generalists are able to develop may impede effective host manipulation and could have resulted in regaining of lipogenic ability in generalist parasitoids". In opposition to the authors who did not find any lipogenesis in L. boulardi, we found a strong increase in lipid quantity in this species for females from desert areas during the first ten days of adult life, evidence that adult lipogenesis occurs in these populations. This is the first evidence that between-populations differences in the ability to synthesize lipids occur in a parasitoid species. Other factors than hosts range may result in existence of lipogenesis in parasitoids, such as host distribution. Lipogenesis may be adaptive in desert areas where females need lipids to fly over large distances and mature eggs once they have found a lot of laying opportunities. Moreover, higher lipid content may limit water loss in this dry climate (Hadley, 1994). The observed adult lipogenesis could explain the longer lifespan and increased egg maturation observed in these females.

Dispersal ability and locomotor activity. Wing loading was lower in females from hot and dry areas than in females from other environments. This reduced wing loading may facilitate flight (Gilchrist \& Huey, 2004) in an environment where females have to move over large distances to find patches of hosts. Greater dispersal ability during the first days of life may compensate for the low number of hosts encounters and be selected because females can search for patches of hosts at lower cost in desert areas.

Flying over large distances to find hosts is an energy demanding activity (Ellers et al., 1998). In a humid environment like that in Chalus or Seyakhal, females do not have to move over such large distances as in a desert environment. In the latter environment, flying, which was not allowed in our experiment, to find laying opportunities may result in a decreased egg maturation and/or longevity. 
Zamankhan females were also more active than females from mild and wet environment. This high activity may have been selected in an environment where females have to move a lot to find hosts in distant patches. Moreover Zamankhan females were more active during the night while females from Chalus and Seyakhal were more active during the day. Avoidance of extreme temperatures in Zamankhan during the day is likely to be adaptive in this desert area. The nocturnal activity of Zamankhan females is the only trait that supports a direct effect of temperature on the evolution of life history traits.

Conclusion. Females from the desert area differed considerably from females originating from the mild coastal region, but these populations were also geographically distant and this separation by distance has allowed local adaptation and caused differences in life histories between populations as a result of selection by the environment.

Differences in temperature and thermal amplitude did not explain our results, but precipitation did. The influence of precipitation on fruit availability, the main nutritional resource for hosts, could explain why this climatic factor is more linked to life history traits than others. Our results, especially synovigeny and lipogenesis, strongly support the hypothesis of selection based on distribution of resources and suggests that host distribution, depending on precipitation, is more important in selection of life history traits of parasitoids than temperature. 


\section{ACKNOWLEDGEMENTS}

This research was supported by the Ministère de l'Enseignement Supérieur et de la Recherche (grant to Joffrey Moiroux) and is part of the Marie Curie Excellence Chair COMPAREVOL (http://comparevol.univ-rennes1.fr/), ECOCLIM program founded by Region Bretagne and CLIMEVOL program founded by the Agence Nationale de la Recherche. We are grateful to Jacintha Ellers for helpful comments on a previous version of this manuscript. 


\section{Literature cited}

Akaike, H. (1974). A new look at the statistical model identification. IEEE Transactions on Automatic Control, 19, 716-723.

Dahlgaard, J., Hasson, E. \& Loeschcke, V. (2001). Behavioral differentiation in oviposition activity in Drosophila buzzatii from highland and lowland populations in Argentina: Plasticity or thermal adaptation? Evolution, 55, 738-747.

Ellers, J. (1996). Fat and eggs: An alternative method to measure the trade-off between survival and reproduction in insect parasitoids. Netherlands Journal of Zoology, 46, 227-235.

Ellers, J. \& van Alphen, J.J.M. (1997). Life history evolution in Asobara tabida: plasticity in allocation of fat reserves to survival and reproduction. Journal of Evolutionary Biology, 10, 771-785.

Ellers, J., van Alphen, J.J.M. \& Sevenster, J.G. (1998). A field study of size fitness relationships in the parasitoid Asobara tabida. Journal of Animal Ecology, 67, 318-324.

Ellers, J. \& Jervis, M. (2004). Why are so few parasitoid wasp species pro-ovigenic? Evolutionary Ecology Research, 6, 993-1002.

Ellers, J., Sevenster, J.G. \& Driessen, G. (2000). Egg Load Evolution in Parasitoids. American Naturalist, 156, 650-665. 
Gilchrist, G.W. \& Huey, R.B. (2004). Plastic and Genetic Variation in Wing Loading as a Function of Temperature Within and Among Parallel Clines in Drosophila subobscura. Integrative and Comparative Biology, 44, 461-470.

Gilchrist, G.W., Jeffers, L.M., West, B., Folk, D.G., Suess, J. \& Huey, R.B. (2008). Clinal patterns of desiccation and starvation resistance in ancestral and invading populations of Drosophila subosbcura. Evolutionary Applications, 1, 513-523.

Giron, D. \& Casas, J. (2003). Lipogenesis in an adult parasitic wasp. Journal of Insect Physiology, 49, 141-147.

Griffiths, J.A., Schiffer, M. \& Hoffmann, A.A. (2005). Clinal variation and laboratory adaptation in the rainforest species Drosophila birchii for stress resistance, wing size, wing shape and development time. Journal of Evolutionary Biology, 18, 213-222.

Hadley, N.F. (1994). Water Relations of Terrestrial Arthropods. Academic Press, London.

Karan D., Dahiya N., Munjal A.K., Gibert P., Moreteau B., Parkash R. \& David J.R. (1998). Desiccation and starvation tolerance of adult Drosophila: Opposite latitudinal clines in natural populations of three different species. Evolution, 52, 825-832.

Kopelman, A.H. \& Chabora, P.C. (1986). Aspects of the reproductive biology of Leptopilina boulardi (Hymenoptera: Eucoilidae). Annals of the Entomological Society of America, 79, 808-813. 
Liefting, M., Hoffmann A.A. \& Ellers, J. (2009). Plasticity versus environmental canalization: population differences in thermal responses along a latitudinal gradient in Drosophila serrata. Evolution, 63, 1954-1963.

Mitrovski, P. \& Hoffmann, A.A. (2001). Postponed reproduction as an adaptation to winter conditions in Drosophila melanogaster: evidence for clinal variation under semi-natural conditions. Proceedings of the Royal Society of London Series B-Biological Sciences, 268, 2163-2168.

Norry, F.M., Sambucetti, P., Scannapieco, A.C. \& Loeschcke, V. (2006). Altitudinal patterns for longevity, fecundity and senescence in Drosophila buzzatii. Genetica, 128, 81-93.

Nunney, L. \& Cheung, W. (1997). The effect of temperature on body size and fecundity in female Drosophila melanogaster: Evidence for adaptive plasticity. Evolution, 51, 1529-1535.

R Development Core Team (2007). R: A language and environment for statistical computing. R Foundation for Statistical Computing. Vienna, Austria. ISBN 3-900051-07-0, URL http://www.R-project.org (accessed March 2007).

Rivero, A. \& West, S.A. (2002). The physiological costs of being small in a parasitic wasp. Evolutionary Ecology Research, 4, 407-420.

Schmidt, P.S. \& Paaby, A.B. (2008). Reproductive diapause and life-history clines in north American populations of Drosophila melanogaster. Evolution, 62, 1204-1215. 
Schmidt, P.S., Matzkin, L., Ippolito, M. \& Eanes, W.F. (2005). Geographic variation in diapause incidence, life-history traits, and climatic adaptation in Drosophila melanogaster. Evolution, 59, 1721-1732.

Sibly, R.M. \& Atkinson, D. (1994). How rearing temperature affects optimal adult size in ectotherms. Functional Ecology, 8, 486-493.

Sørensen, J.G., Norry, F.M., Scannapieco, A.C. \& Loeschcke, V. (2005). Altitudinal variation for stress resistance traits and thermal adaptation in adult Drosophila buzzatii from the New World. Journal of Evolutionary Biology, 18, 829-837.

Starmer W.T. \& Wolf, L.L. (1989). Causes of variation in wing loading among Drosophila species. Biological Journal of the Linnean Society, 37, 247-261.

Stearns, S. C. (1992). The Evolution of Life Histories, Oxford University Press.

Terblanche, J.S., Klok, C.J. \& Chown, C.L. (2004). Metabolic rate variation in Glossina pallidipes (Diptera: Glossinidae): gender, ageing and repeatability. Journal of Insect Physiology, 50, 419-428.

Unwin D.M. \& Corbet S.A. (1984). Wingbeat frequency, temperature and body size in bees and flies. Physiological Entomology, 9, 115-121.

Varaldi, J., Fouillet, P., Ravallec, M., Lopez-Ferber, M., Bouletreau, M. \& Fleury, F. (2003). Infectious behavior in a parasitoid. Science, 302, 1930-1930. 
Vernon, P. \& Vannier, G. (1996). Developmental patterns of supercooling capacity in a subantarctic wingless fly. Experientia, 52, 155-158.

Visser, B. \& Ellers, J. (2008). Lack of lipogenesis in parasitoids: A review of physiological mechanisms and evolutionary implications. Journal of Insect Physiology, 54, 1315-1322.

Visser, B., Le Lann, C., den Blanken, F.J., Harvey, J.A., van Alphen, J.J.M., Ellers, J. (2010). Loss of lipid synthesis as an evolutionary consequence of a parasitic lifestyle. Proceedings of the National Academy of Sciences of the United States of America, 107, 8677-8682. 
Table 1. Climatic data recorded for the four sampled areas, from 1977 to 2005 for Chalus, 1955 to 2005 for Seyakhal and Zamankhan, 1993 to 2003 for Sorkhabad, 1951 to 2005 for Dorcheh (Source: Islamic Republic Of Iran Meteorological Organization). We considered the average of each parameter measured every day from April to September, which is the period of activity of Leptopilina boulardi. Thermal amplitude was calculated as the mean of the differences between maximum and minimum air temperature per month.

\begin{tabular}{cccccc}
\hline $\begin{array}{c}\text { Sampling } \\
\text { areas }\end{array}$ & $\begin{array}{c}\text { Temperature } \\
\left({ }^{\circ} \mathrm{C}\right)\end{array}$ & $\begin{array}{c}\text { Thermal } \\
\text { amplitude }\left({ }^{\circ} \mathrm{C}\right)\end{array}$ & $\begin{array}{c}\text { Relative } \\
\text { humidity }(\%)\end{array}$ & $\begin{array}{c}\text { Number of } \\
\text { rainy days }\end{array}$ & $\begin{array}{c}\text { Precipitation } \\
\text { amount }(\mathrm{mm})\end{array}$ \\
\hline Chalus & 26.3 & 7.6 & 80 & 43.3 & 248 \\
Seyakhal & 26.4 & 9.8 & 79 & 56.7 & 433 \\
Sorkhabad & 24.4 & 16.7 & 44 & 28.6 & 105 \\
Dorcheh & 31.6 & 15.6 & 29.7 & 14.2 & 30.9 \\
Zamankhan & 28.6 & 19.2 & 36 & 13.8 & 55 \\
\hline
\end{tabular}




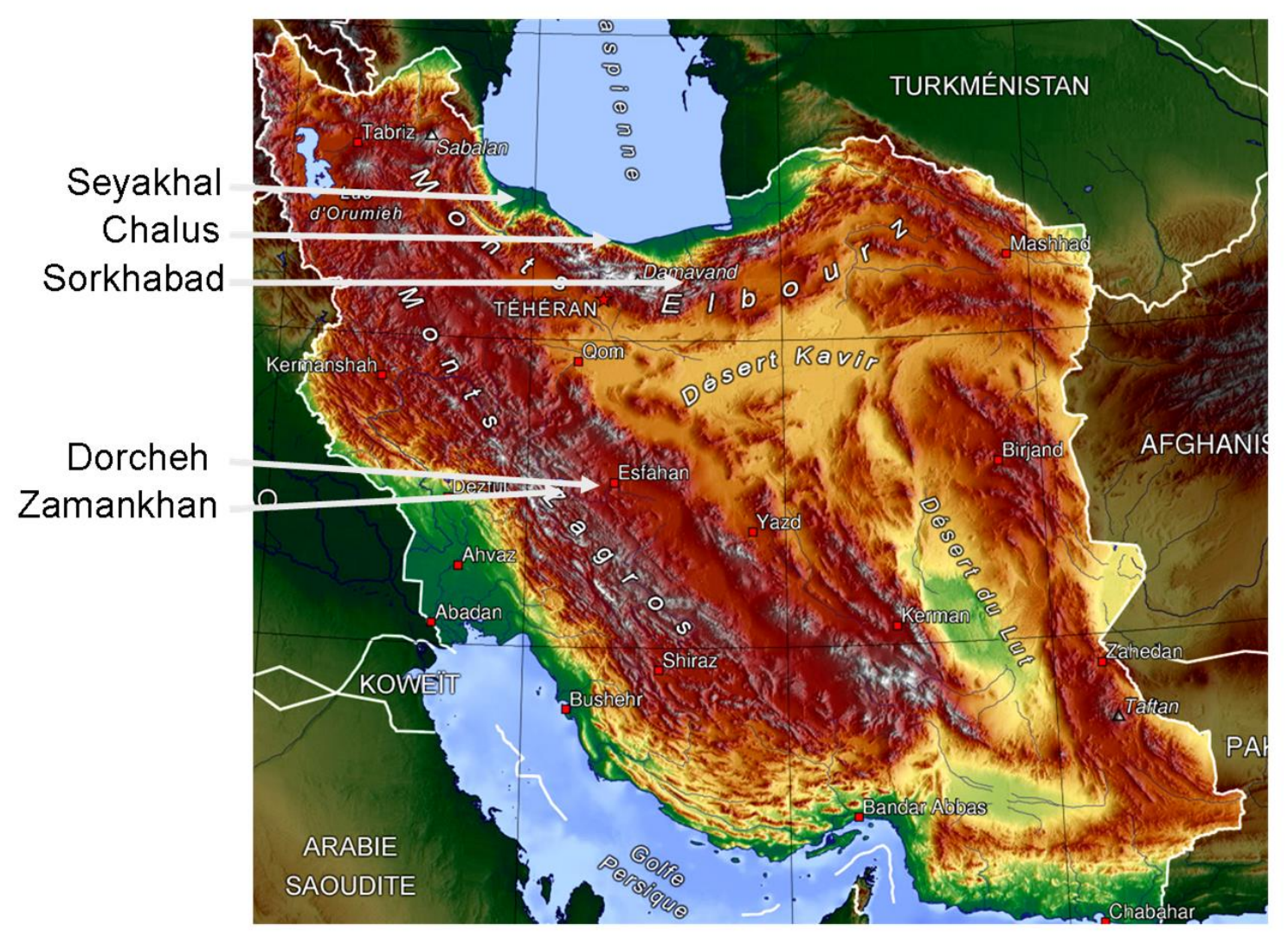

Fig. 1. Map of Iran; the arrows indicate the five Leptopilina boulardi sampling sites. 


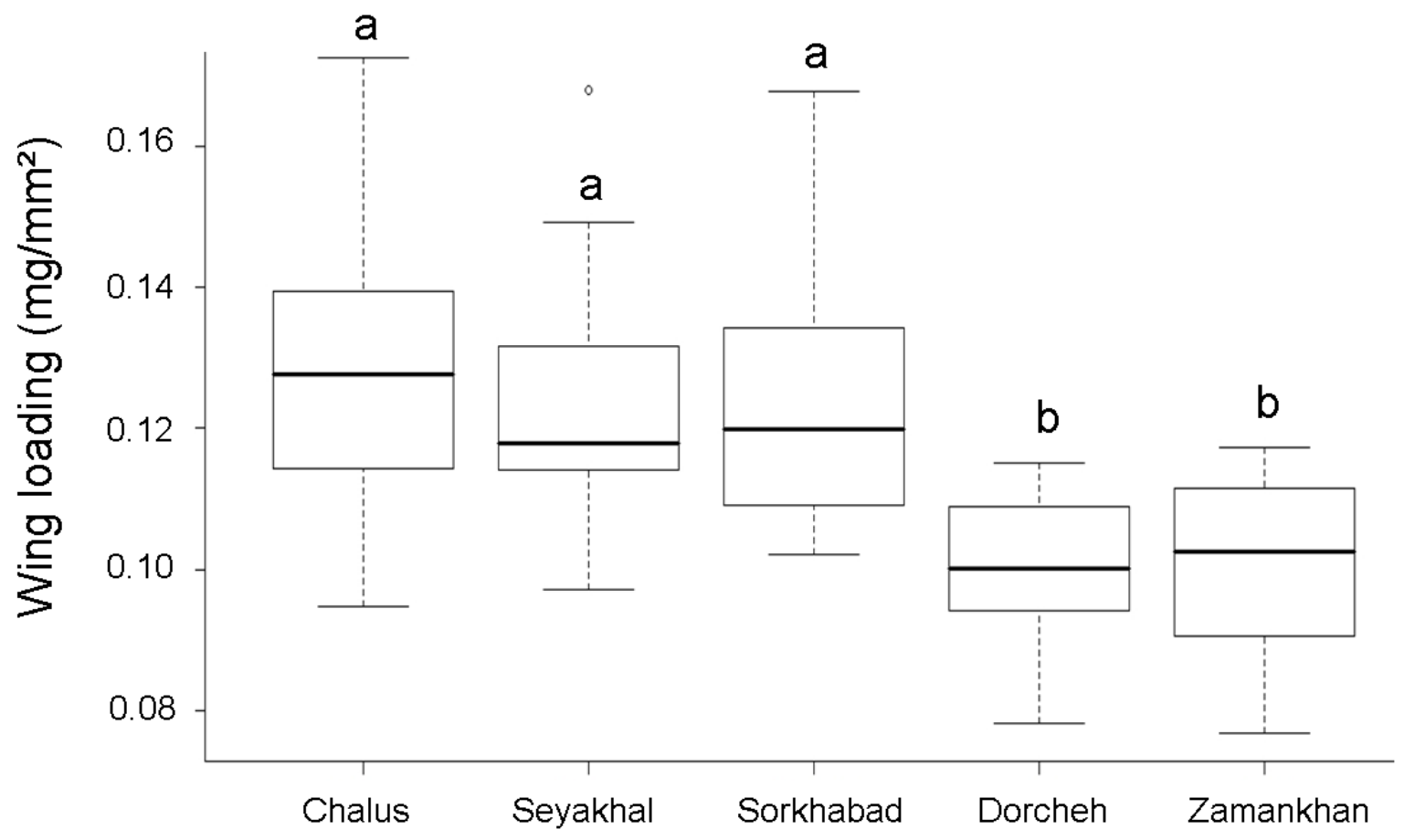

Fig. 2. Wing loading measured at emergence for Chalus, Seyakhal, Sorkhabad, Dorcheh and Zamankhan females. Different letters indicate significant differences of wing loading between populations $(\mathrm{n}=20$ per population, $\mathrm{P}<0.05)$. Error bars: \pm SE. 

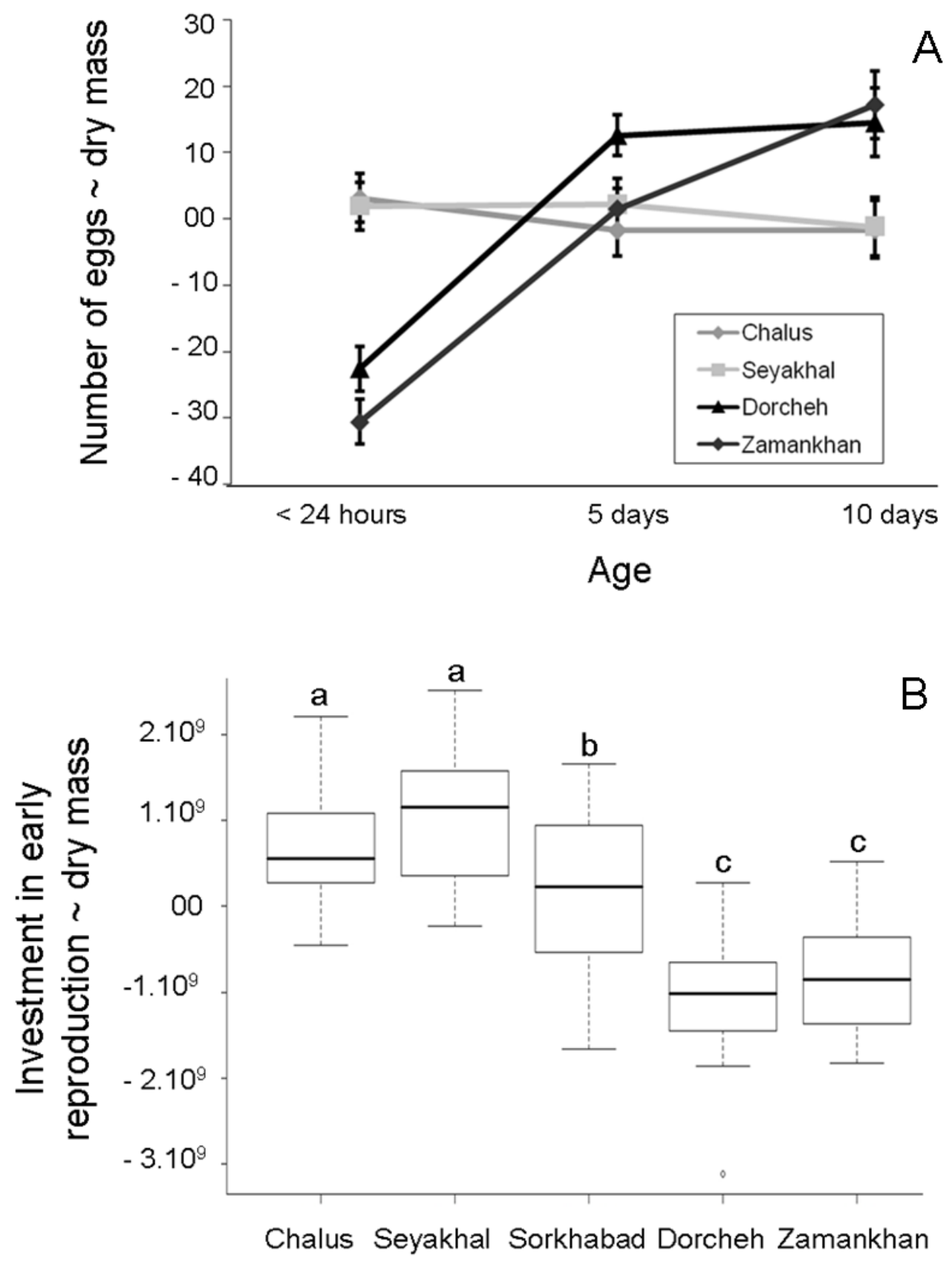

Fig. 3. (a). Plot of residuals of models comparing mean number of eggs at 24 hours, 5 days and 10 days of adult life with lean dry mass as covariate. A model was established for each population. The higher the residuals, the more females of a same lean dry mass have eggs in their ovaries $(n=20$ per age per population). Error bars: \pm SE. (b) Plot of residuals of a model comparing investment in early reproduction (=number of eggs $\mathrm{x}$ volume of eggs) between populations with lean dry mass as covariate. The model was established with the global data set. The highest the residuals, the more females of a same lean dry mass invested in reproduction. Different letters indicate significant differences of investment in reproduction between populations $(n=20$ per population, $P<0.05)$. Error bars: \pm SE . 

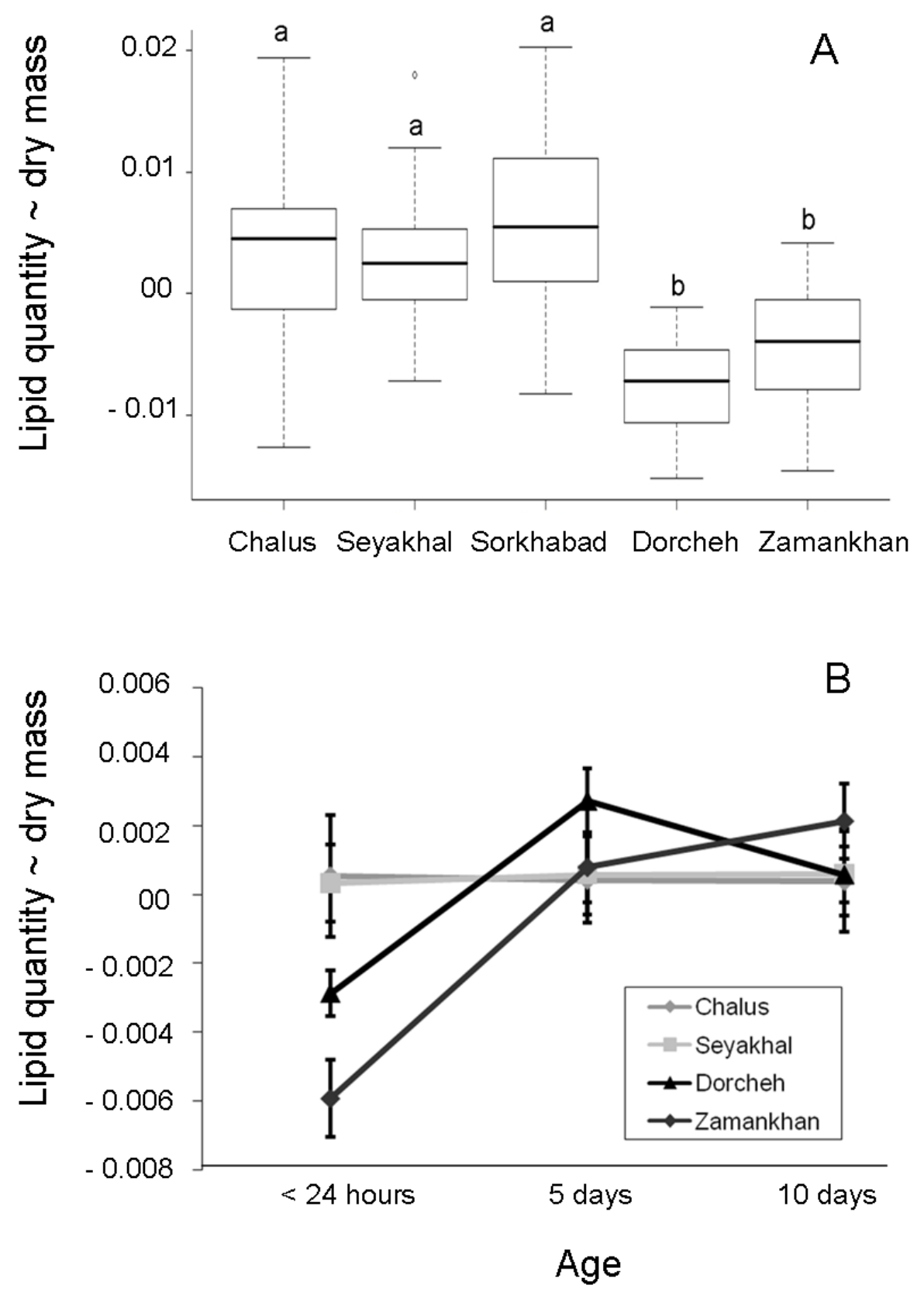

Fig. 4. (a) Plot of residuals of a model comparing lipid quantity between populations with lean dry mass as covariate at emergence. The model was established with the global data set. The highest the residuals, the more females of a same lean dry mass have lipid reserves. Different letters indicate significant differences of lipid content between populations $(n=20$ per population, $P<0.05)$. Error bars: \pm SE. (b) Plot of residuals of models comparing lipid quantity at 24 hours, five days and ten days of adult life with lean dry mass as covariate. A model was established for each population. The higher the residuals, the more females of a same lean dry mass have lipid reserves. Error bars: \pm SE. ( $n=20$ per age per population). 

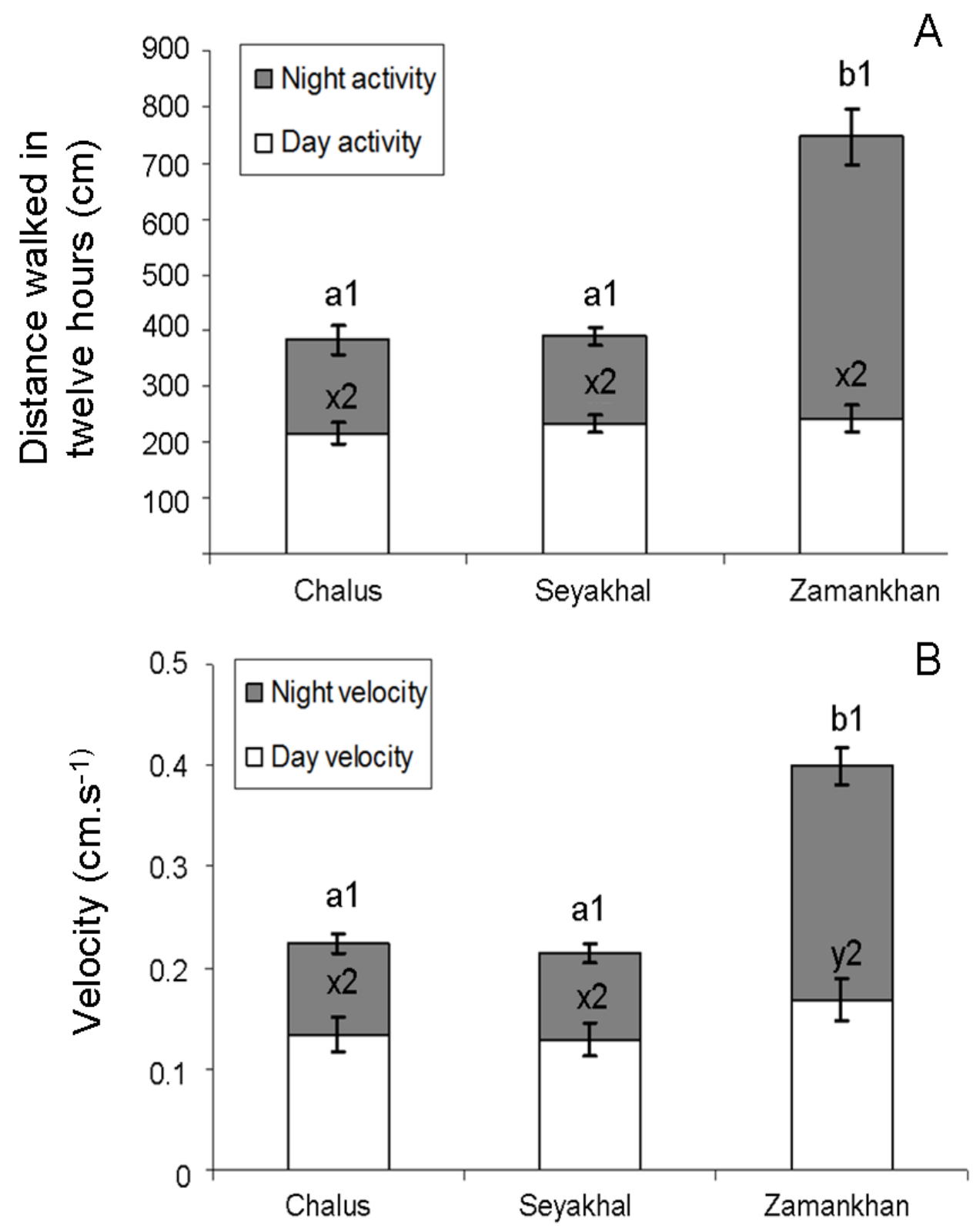

Fig. 5. (a) Mean distance walked during twelve-hours day and night recordings, measured with Ethovision software. Different letters indicate significant differences of activity between populations. Different numbers mean significant differences of activity between day and night recordings for a single population $(\mathrm{n}=20$ per treatment perpopulation, $\mathrm{P}<0.05)$. Error bars $: \pm \mathrm{SE}$. (b) Mean velocity during twelve-hours day and night recordings, measured with Ethovision software. Different letters indicate significant differences of velocity between populations. Different numbers indicate significant differences of velocity between day and night recordings for a single population $(n=20$ per treatment per population, $P<0.05)$. Error bars : \pm SE. 


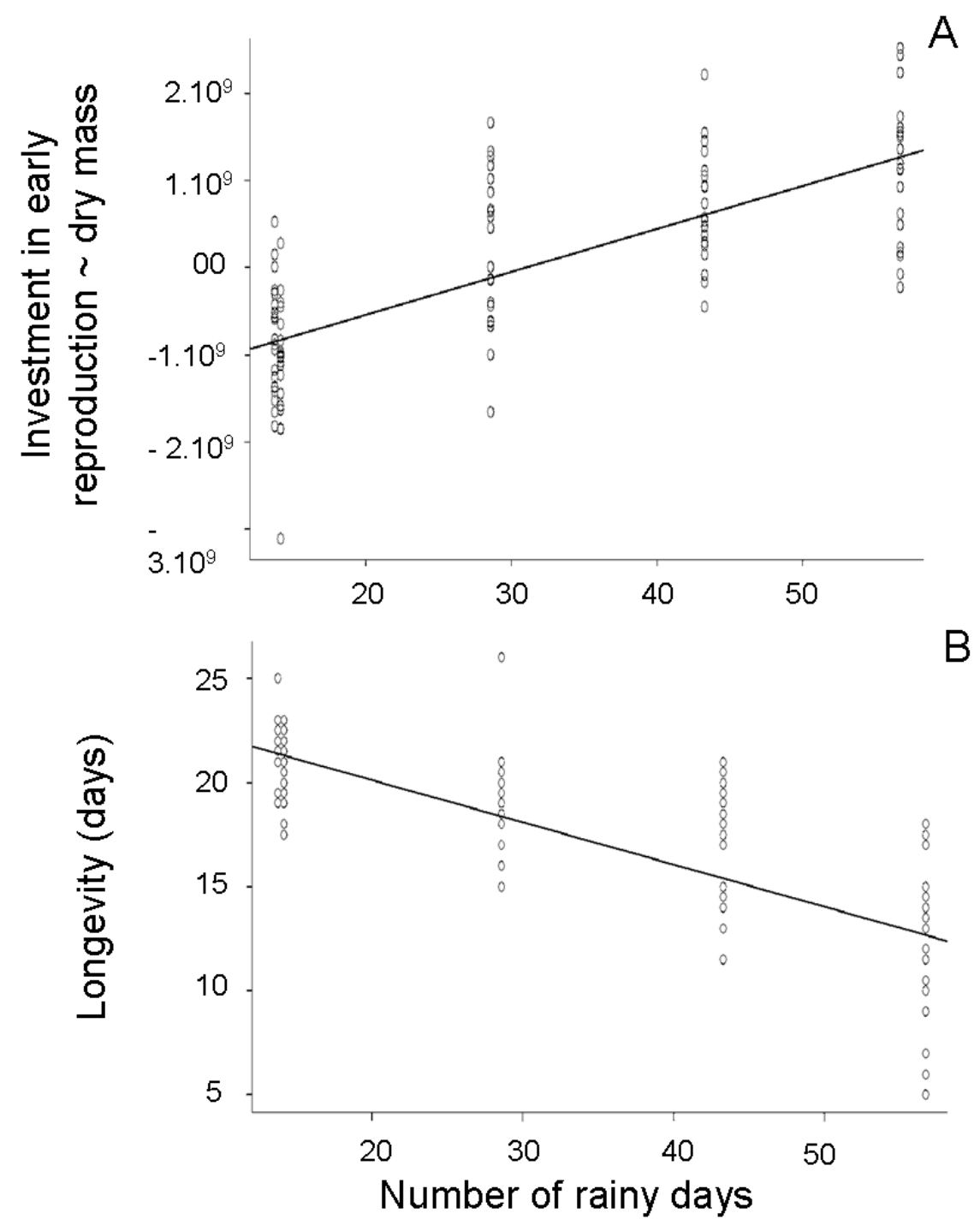

Fig. 6 (a) Plot of a generalized additive model realized on investment in early reproduction with lean dry mass as covariate and number of rainy days as an explanatory factor. Relative humidity, number of rainy days and precipitation amount had to be included as explanatory factors to obtain the minimum adequate model for this life history trait. Here we represent the plot of a model on investment in early reproduction with the more significant factor in our model, the number of rainy days. (b) Plot of a generalized additive model realized on longevity with number of rainy days as an explanatory factor. Relative humidity, number of rainy days and precipitation amount had to be included as explanatory factors to obtain the minimum adequate model for this life history trait. Here we represent the plot of a model on longevity with the more significant factor in our model, the number of rainy days. 